\title{
Effect of endoplasmic reticulum calcium on paraquat-induced apoptosis of human lung type II alveolar epithelial A549 cells
}

\author{
CHUN-QING SONG, DA-ZHUANG SUN, YONG-MIN XU, CHEN YANG, QUAN CAI and XUE-SONG DONG
}

Department of Emergency, The First Affiliated Hospital of China Medical University, Shenyang, Liaoning 110001, P.R. China

Received November 1, 2018; Accepted May 3, 2019

DOI: $10.3892 / \mathrm{mmr} .2019 .10469$

\begin{abstract}
The present study aimed to explore the role of endoplasmic reticulum calcium $\left(\mathrm{ER} \mathrm{Ca}^{2+}\right)$ in the apoptosis of human lung type II alveolar epithelial A549 cells induced by paraquat (PQ) in vitro. PQ significantly elevated the intracellular $\mathrm{Ca}^{2+}$ concentration. Treatment with the $\mathrm{Ca}^{2+}$-ATPase inhibitor thapsigargin significantly increased PQ-induced cytotoxicity, elevated the intracellular level of $\mathrm{Ca}^{2+}$, and increased the apoptosis rate, the protein expression of glucose-regulated protein 78 (GRP78) and C/EBP homologous protein (CHOP), and the activities of caspase-7 and caspase-12 in PQ-treated cells. By contrast, treatment with heparin, an inositol 1,4,5-triphosphate receptor inhibitor, remarkably attenuated cytotoxicity and decreased the intracellular level of $\mathrm{Ca}^{2+}$, the apoptosis rate and the expression levels of GRP78, CHOP and Caspases. In conclusion, PQ impaired the regulating function of $\mathrm{ER} \mathrm{Ca}^{2+}$ and resulted in an excessive increase of intracellular $\mathrm{Ca}^{2+}$. Therefore, influencing the $\mathrm{Ca}^{2+}$ signaling in the ER influenced the apoptosis of A549 cells via the ER stress pathway.
\end{abstract}

\section{Introduction}

Paraquat (PQ), also known as 1,1'-dimethyl-4,4'-bipyridinium dichloride, is a highly effective quaternary ammonium herbicide that has been widely used in agriculture worldwide (1). Its misuse by humans can result in multiple organ dysfunction and lung injury, and this compound has an extremely high fatality rate with no specific antidote available (2). To date, the mechanism involved in the toxic effect of PQ remains unknown. Certain studies have indicated that the apoptosis of alveolar epithelial cells is a key in the early manifestation of pulmonary fibrosis caused by PQ $(3,4)$. Previous studies have

Correspondence to: Dr Xue-Song Dong, Department of Emergency, The First Affiliated Hospital of China Medical University, 155 Nanjing North Street, Heping, Shenyang, Liaoning 110001, P.R. China E-mail: xuesongdongdr@163.com

Key words: paraquat, A549 cells, $\mathrm{Ca}^{2+}$, apoptosis, endoplasmic reticulum stress also revealed that PQ induced the apoptosis of human lung type II alveolar epithelial A549 cells mediated by the endoplasmic reticulum stress (ERS) pathway (5).

Calcium $\left(\mathrm{Ca}^{2+}\right)$, an important signal transduction molecule in the endoplasmic reticulum (ER), drives the cell apoptosis by ERS and mitochondrial apoptosis pathway (6). The highest concentration of $\mathrm{Ca}^{2+}$ in cells is found in the ER, and thus the ER serves an important role in maintaining the $\mathrm{Ca}^{2+}$ stability. $\mathrm{Ca}^{2+}$ homeostasis in cells is achieved through the $\mathrm{Ca}^{2+}$-ATP enzyme pump in the ER, which absorbs $\mathrm{Ca}^{2+}$ from the cytoplasm, and inositol 1,4,5-triphosphate receptor (IP3R), which regulates the release of $\mathrm{Ca}^{2+}$ from the ER (7). When the $\mathrm{Ca}^{2+}$ homeostasis in the ER is damaged, physiopathological changes in cells occur, such as ERS, changes in mitochondrial membrane permeability, the release of cytochrome $c$, and dysregulation of B-cell lymphoma 2 ( $\mathrm{Bcl}-2)$ and $\mathrm{Bcl}-2$-associated $\mathrm{X}$ protein, which results in cell apoptosis $(8,9)$. However, it is unclear whether $\mathrm{ER} \mathrm{Ca}^{2+}$ plays an important role during the apoptosis of human lung type II alveolar epithelial A549 cells induced by PQ.

Therefore, in the present study, the $\mathrm{Ca}^{2+}$-ATP enzyme inhibitor thapsigargin and the IP3R inhibitor heparin were used to preprocess A549 cells, followed by exposure to PQ to induce cell apoptosis. The cell activity, nuclear form, $\mathrm{Ca}^{2+}$ concentration, apoptosis rate, expression levels of the ERS marker proteins glucose-regulated protein 78 (GRP78) and $\mathrm{C} / \mathrm{EBP}$ homologous protein (CHOP), and changes in caspase-7/12 activity were detected to determine whether ER $\mathrm{Ca}^{2+}$ was involved in the PQ-induced apoptosis of human lung type II alveolar epithelial A549 cells. This was explored to provide a theoretical basis for the clinical treatment of $\mathrm{PQ}$ poisoning.

\section{Materials and methods}

Cells and reagents. The A549 cell line was obtained from The Chinese Academy of Sciences Cell Bank. RPMI-1640 medium was purchased from GE Healthcare Life Sciences (Hyclone; Logan, UT, USA) and fetal bovine serum (FBS) was from Gemini Bio-Products, Inc. PQ and trypsin were purchased from Merck KGaA (Sigma-Aldrich), heparin and thapsigargin were obtained from Beijing Solarbio Science and Technology Co., Ltd. (Beijing, China), while Hoechst 33258 stain was from Beyotime Institute of Biotechnology (Shanghai, China). The Annexin V-FITC/PI kit was purchased from 
Dojindo Molecular Technologies, Inc. (Kumamoto, Japan), Calcium detection kit and the Caspase activity kit was from Nanjing Keygen Biotech Co., Ltd. (Nanjing, China). Antibodies against GRP78 (cat. no. 66574-1-Ig), CHOP (cat. no. 15204-1-AP) and $\beta$-actin (cat. no. HRP-60008) were purchased from ProteinTech Group, Inc. Horseradish peroxidase-conjugated goat anti-rabbit (cat. no. ab6721) goat anti-mouse immunoglobulin G secondary antibodies (cat. no. ab97040) and ECL Substrate kit (cat. no. ab133406) were purchased from Abcam.

Cell culture and grouping. A549 cells were cultured in RPMI-1640 culture solution with $10 \%$ FBS in an incubator with $5 \% \mathrm{CO}_{2}$ at $37^{\circ} \mathrm{C}$. The culture solution was changed every other day. At 70-80\% confluence, cells were divided into six experimental groups, as follows: i) Control group, exposed to equal volume of PBS; ii) heparin group, preprocessed with heparin $(200 \mu \mathrm{g} / \mathrm{ml})$ for $2 \mathrm{~h}$; iii) thapsigargin group, preprocessed with thapsigargin $(4 \mu \mathrm{M})$ for $2 \mathrm{~h}$; iv) PQ group, exposed to PQ (200 M); v) heparin + PQ group, preprocessed with heparin $(200 \mu \mathrm{g} / \mathrm{ml})$ for $2 \mathrm{~h}$, followed by PQ $(200 \mu \mathrm{M})$ treatment; vi) thapsigargin $+\mathrm{PQ}$ group, preprocessed with thapsigargin $(4 \mu \mathrm{M})$ for $2 \mathrm{~h}$, followed by PQ $(200 \mu \mathrm{M})$ treatment. Cells in each group were cultured for $48 \mathrm{~h}$, and a number of relevant indexes were then tested.

Cell activity detection by MTT assay. A total of $1 \times 10^{5}$ cells $/ \mathrm{ml}$ were seeded onto a 96-well plate, with each well containing $100 \mu \mathrm{l}$ of solution, and cultured for $24 \mathrm{~h}$. Next, the cells were treated accordingly in the different groups and continuously cultured for $48 \mathrm{~h}$ after treatment. A total of $20 \mu 1$ MTT solution $(5 \mathrm{mg} / \mathrm{ml})$ was added into each well and mixed, and the cells were continuously cultured for $4 \mathrm{~h}$ in an incubator with $5 \% \mathrm{CO}_{2}$ at $37^{\circ} \mathrm{C}$. Subsequently, the supernatant was discarded, and $150 \mu \mathrm{l}$ DMSO was added to each well. The cells were shaken in the dark for 10 min to dissolve the formazan crystals. A microplate reader at $490 \mathrm{~nm}$ was used to determine the optical density (OD) of each well.

Cell apoptosis detection by Hoechst 33258 staining. The culture solution was discarded after $48 \mathrm{~h}$ of incubation, and the cells were collected. Paraformaldehyde (4\%) was added to fix for $10 \mathrm{~min}$ at room temperature. The fixation solution was then discarded, and the cells were washed three times with PBS. Next, Hoechst 33258 stain was added for $5 \mathrm{~min}$ and then discarded after washing three times with PBS. After mounting with an anti-fluorescence quenching agent the cell nuclei were observed under a microscope.

Cell apoptosis rate detection using the Annexin V-FITC/propidium iodide (PI) double-staining method. A549 cells were seeded onto a 6 -well plate at a density of $1 \times 10^{6}$ cells/well. When cells reached $70 \%$ confluence, they were processed accordingly in the different groups, and continuously cultured for $48 \mathrm{~h}$. After the $48 \mathrm{~h}$ culture, cells in each group were collected, washed three times with PBS, and then incubated with a mixture containing $5 \mu 1$ Annexin V-FITC and $5 \mu \mathrm{l}$ PI for $15 \mathrm{~min}$ at room temperature in the dark. A flow cytometer was subsequently used for the detection of apoptosis rate.
Measurement of $\mathrm{Ca}^{2+}$ concentration. Cells collected from each group were placed into culture solutions with $1.25 \mu \mathrm{M}$ Fluo-3 AM probe of the Calcium Detection Kit (Nanjing Keygen Biotech Co., Ltd.) and incubated for $30 \mathrm{~min}$ at $37^{\circ} \mathrm{C}$ in the dark. Subsequent to incubation, the cells were washed three times with PBS and resuspended in $300 \mu$ PBS in a flow tube. A flow cytometer was then used for the detection of $\mathrm{Ca}^{2+}$ concentration.

Detection of the protein expression levels of GRP78 and CHOP by western blot analysis. Cells collected from each group were washed three times with PBS and lysed with a lysis buffer consisting of dichloroacetic acid (0.1\%), PMSF $(1 \mathrm{mM})$, protease inhibitor cocktail $(10 \mu \mathrm{M}), \mathrm{Na}_{3} \mathrm{PO}_{4}(1 \mathrm{mM})$, Triton X-100 (1\%), NaCl (150 mM), Tris- $\mathrm{HCl}(10 \mathrm{mM})$, EDTA $(1 \mathrm{mM})$ and EGTA $(1 \mathrm{mM})$. Next, centrifugation was performed for $30 \mathrm{~min}$ at $14,000 \mathrm{xg}$ at $4^{\circ} \mathrm{C}$, and the supernatant was collected and transferred into a new EP tube. The BCA method was then used to measure the protein concentration. Subsequently, $30 \mu \mathrm{g}$ of the sample was loaded and separated by $12 \%$ SDS-PAGE at $4^{\circ} \mathrm{C}$ at $70 \mathrm{~V}$ for $60 \mathrm{~min}$. The protein was then transferred to a PVDF membrane and incubated for $2 \mathrm{~h}$ at room temperature with blocking solution that consisted of 5\% nonfat milk powder dissolved in Tris-buffered saline/Tween-20 (TBST). Antibodies targeting GRP78 (1:500), CHOP $(1: 1,000)$ and $\beta$-actin $(1: 1,000)$ were added, and the membrane was fixed overnight at $4{ }^{\circ} \mathrm{C}$ and maintained at room temperature for $2 \mathrm{~h}$. Subsequent to washing three times with TBST, secondary antibodies $(1: 5,000)$ were added to the PVDF membrane, maintained at room temperature for $2 \mathrm{~h}$ and washed three times with TBST. An ECL kit was used to visualize the protein bands. Finally, the image was developed and fixed, while ImageJ software (National Institutes of Health, Bethesda, MD, USA) was used to perform gray analysis.

Caspase activity detection. Cells collected from each group were washed three times with PBS. Lysis solution was added in moderation for $2 \mathrm{~h}$ on ice, and centrifugation was performed for $1 \mathrm{~min}$ at $11,000 \mathrm{xg}$ at $4^{\circ} \mathrm{C}$. The supernatant was collected and transferred into a new EP tube, and the BCA method was used to measure the protein concentration. Next, $50 \mu \mathrm{l}$ of $2 \mathrm{X}$ buffer solution and $5 \mu \mathrm{l}$ caspase substrate was added to $50 \mu \mathrm{l}$ cell lysis product (containing $150 \mu \mathrm{g}$ of protein), and incubated for $4 \mathrm{~h}$ at room temperature in the dark. The OD at $405 \mathrm{~nm}$ was measured using a microplate reader.

Statistical analysis. SPSS software (version 20.0; IBM Corporation, Armonk, NY, USA) was used to perform the statistical analysis. The data in each group are expressed as the mean \pm standard deviation. Intergroup differences were assessed by one-way analysis of variance. If equal variance was assumed, Dunnett's test was used for comparisons between the two groups, whereas if unequal variance was assumed, Dunnett's T3 test was used. $\mathrm{P}<0.05$ was considered to indicate a statistically significant difference.

\section{Results}

Changes in cell activity. Compared with the control group, there were no evident changes in the heparin and thapsigargin 
groups, which indicated that the concentrations of heparin and thapsigargin used in the present study exerted no cytotoxicity (Fig. 1). However, the cell activity in the PQ group was significantly decreased, which indicated that the concentration of PQ used in the present study had a strong toxic effect on A549 cells. Compared with the PQ group, the cell activity was significantly increased in the heparin + PQ group, while cell activity was significantly decreased in the thapsigargin $+\mathrm{PQ}$ group. These results suggested that the inhibitionof $\mathrm{ER} \mathrm{Ca}^{2+}$ release was able to alleviate the cytotoxicity exerted by PQ, while the inhibition of ER $\mathrm{Ca}^{2+}$ absorption resulted in aggravation of cytotoxicity (Fig. 1). Taken together, these findings indicated that the cytotoxicity of PQ is correlated with the $\mathrm{Ca}^{2+}$ signal.

Changes in nuclear form. Compared with the control group, there were no evident changes in the nuclear form in the heparin and thapsigargin groups (Fig. 2). By contrast, characteristic changes, such as karyopyknosis, karyorrhexis and nuclear apoptosis, appeared at different degrees in the PQ, heparin + PQ and thapsigargin + PQ groups. Compared with the PQ group, fewer changes were observed in the nuclear form in the heparin + PQ group, while the nuclear form changes in the thapsigargin + PQ group were more prominent (Fig. 2) These findings indicated that $\mathrm{Ca}^{2+}$ signal had an effect on the A549 cell apoptosis induced by PQ.

Changes in cell apoptosis rate. Compared with the control group, there were no evident changes in the heparin and thapsigargin groups, which indicated that the concentrations of heparin and thapsigargin used in the experiments of the present study had no significant cytotoxic effect. However, in the PQ group, the cell apoptosis rate was significantly enhanced, which suggested that the concentration of PQ used in the present study was able to strongly induce A549 cell apoptosis (Fig. 3). In order to determine whether the $\mathrm{Ca}^{2+}$ signals of ER affect the rate of cell apoptosis induced by PQ, the apoptosis rate was measured in PQ-treated cells that were preprocessed with thapsigargin or heparin. As presented in Fig. 3, the cells apoptosis rates in the PQ, heparin + PQ and thapsigargin + PQ groups were increased by different levels compared with the control group. When compared with the PQ group, the cell apoptosis rate was significantly decreased in the heparin + PQ group, but was significantly increased in the thapsigargin + PQ group. These results further revealed that the $\mathrm{Ca}^{2+}$ signal of ER participated in the A549 cell apoptosis induced by PQ.

Changes in $\mathrm{Ca}^{2+}$ concentration in cells. $\mathrm{Ca}^{2+}$ is known to be an important signal transduction factor in eukaryotic cells, and maintaining its homeostasis serves an important role in the normal physiological activity of cells (10). $\mathrm{Ca}^{2+}$ overload in cells is usually an early manifestation of cell apoptosis and death. The $\mathrm{Ca}^{2+}$ influx from outside the cell, the activities of $\mathrm{Ca}^{2+}$ stores in the cells, and changes in $\mathrm{Ca}^{2+}$ spatial distribution may cause $\mathrm{Ca}^{2+}$ overload in cells (11). In order to investigate the influence of PQ on $\mathrm{Ca}^{2+}$ concentration in cells, a Fluo-3 AM fluorescent probe was used to detect the changes in $\mathrm{Ca}^{2+}$ concentration. The results revealed that, compared with the control group, the $\mathrm{Ca}^{2+}$ concentration in cells treated with PQ

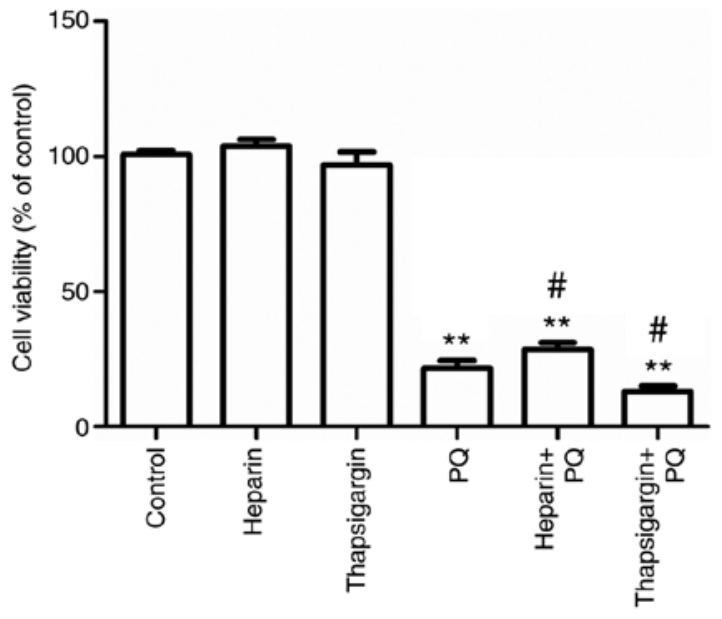

Figure 1. A549 cells were processed accordingly in the different groups for $48 \mathrm{~h}$, and then MTT assay was performed to detect the cell activity. ${ }^{* * *} \mathrm{P}<0.01$ vs. control group; ${ }^{\#} \mathrm{P}<0.05$ vs. $\mathrm{PQ}$ group. $\mathrm{PQ}$, paraquat.

was significantly increased, indicating that PQ induced $\mathrm{Ca}^{2+}$ overload in cells (Fig. 4). Heparin, an inhibitor of IP3R in the $\mathrm{ER}$, and thapsigargin, an inhibitor of sarco-ER $\mathrm{Ca}^{2+}$-ATPases in the ER, were used to determine the association between $\mathrm{Ca}^{2+}$ overload in the cells and $\mathrm{Ca}^{2+}$ in the ER. The results indicated that, compared with the PQ group, $\mathrm{Ca}^{2+}$ fluorescence intensity was significantly decreased in the heparin + PQ group, indicating that heparin prevented the release of $\mathrm{Ca}^{2+}$ in the ER and significantly reversed the increase in $\mathrm{Ca}^{2+}$ concentration induced by PQ. By contrast, a marked increase in $\mathrm{Ca}^{2+}$ fluorescence intensity was observed in the thapsigargin + PQ group as compared with the PQ group (Fig. 4). These aforementioned results suggested that $\mathrm{Ca}^{2+}$ overload in the cells existed during the A549 cell apoptosis induced by PQ, and that the ER served an important role in the imbalance of $\mathrm{Ca}^{2+}$ and outflow of $\mathrm{Ca}^{2+}$.

Changes in GRP78 and CHOP protein levels. In order to determine whether PQ induced ERS in A549 cells, the expression levels of two relevant proteins, GRP78 and CHOP, were determined. The results demonstrated that, compared with the control group, there were no evident changes in the heparin and thapsigargin groups, whereas the levels of the two proteins were significantly increased in the PQ group (Fig. 5). This suggested that PQ significantly induced ERS during the induction of A549 cell apoptosis. Compared with the PQ group, the expression levels of GRP78 and CHOP were significantly decreased in the heparin + PQ group and significantly increased in the thapsigargin + PQ group (Fig. 5). These results indicated that the intervention of $\mathrm{Ca}^{2+}$ release and absorption in the ER influenced the ERS.

Changes in caspase-7/12 activity. caspase-7 and caspase-12 are members of the Caspase protein family, and are defined as the executive proteins in cell apoptosis. The activation of caspase-7 and caspase-12 is necessary for the ERS-induced cell apoptosis. In the present study, the expression levels of caspase-7 and caspase-12 in each group was detected to determine whether PQ was able to promote $\mathrm{Ca}^{2+}$ release and reduce $\mathrm{Ca}^{2+}$ absorption, and influence and trigger A549 cell apoptosis mediated by ERS. As shown in the Fig. 6, the activities of caspase-7 


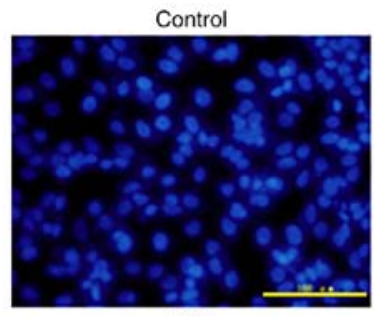

$P Q$

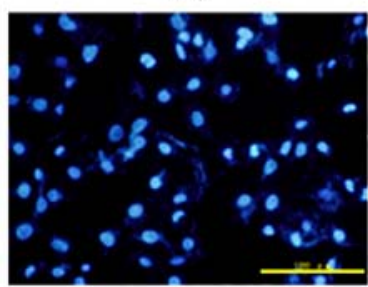

Heparin

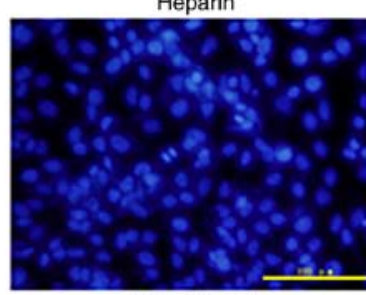

Heparin $+\mathrm{PQ}$

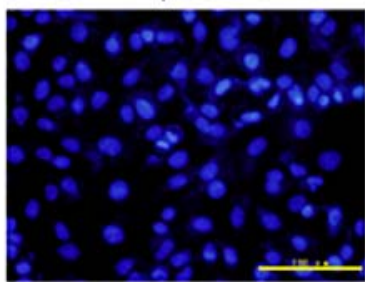

Thapsigargin

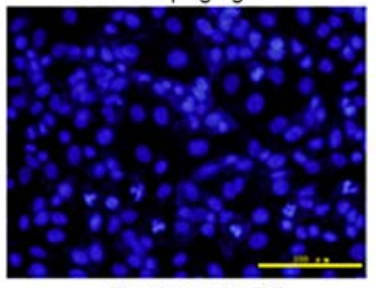

Thapsigargin $+\mathrm{PQ}$

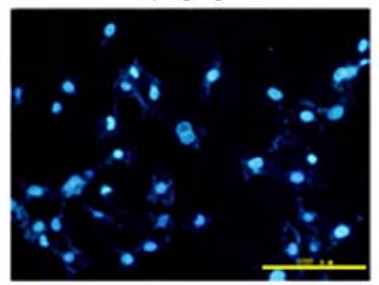

Figure 2. A549 cells were processed accordingly in the different groups for $48 \mathrm{~h}$, and then changes in the nuclear form were observed by Hoechst 33258 staining. Magnification, x200. PQ, paraquat.
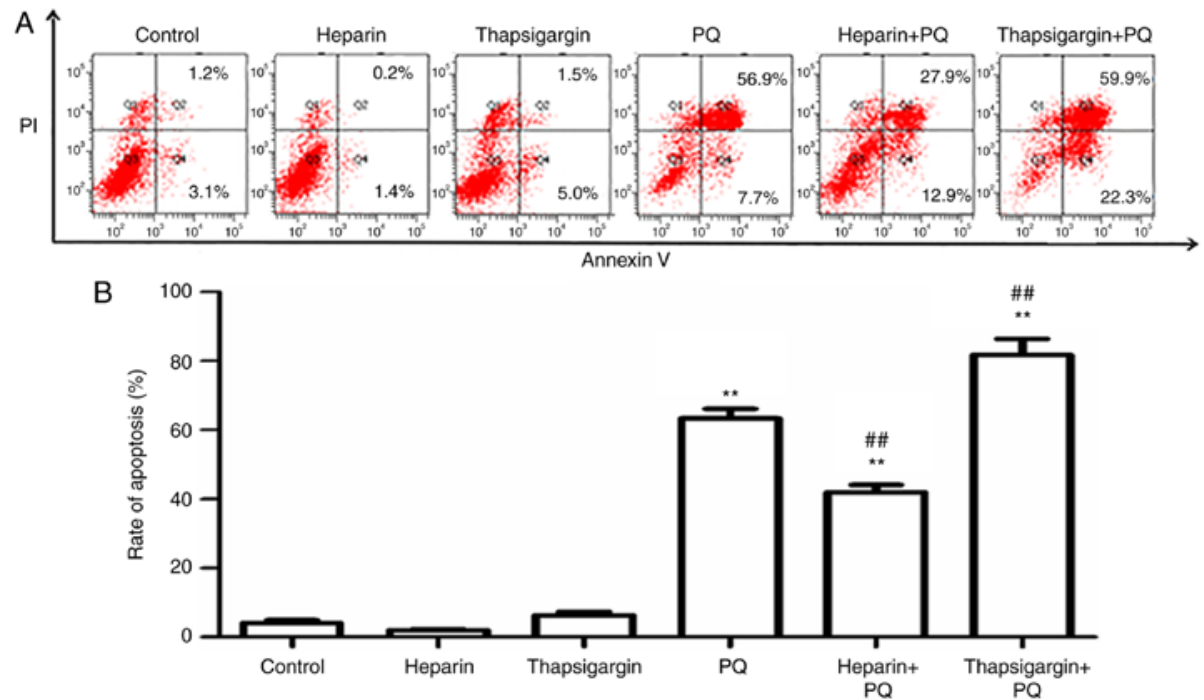

Figure 3. A549 cells were processed accordingly in the different groups for $48 \mathrm{~h}$, and then changes in apoptosis rate were detected using a flow cytometer (A) Flow cytometric analysis, and (B) statistical analysis of the apoptosis rate in each group. ${ }^{* *} \mathrm{P}<0.01$ vs. control group; ${ }^{\# \#} \mathrm{P}<0.01$ vs. $\mathrm{PQ}$ group. $\mathrm{PQ}$, paraquat.
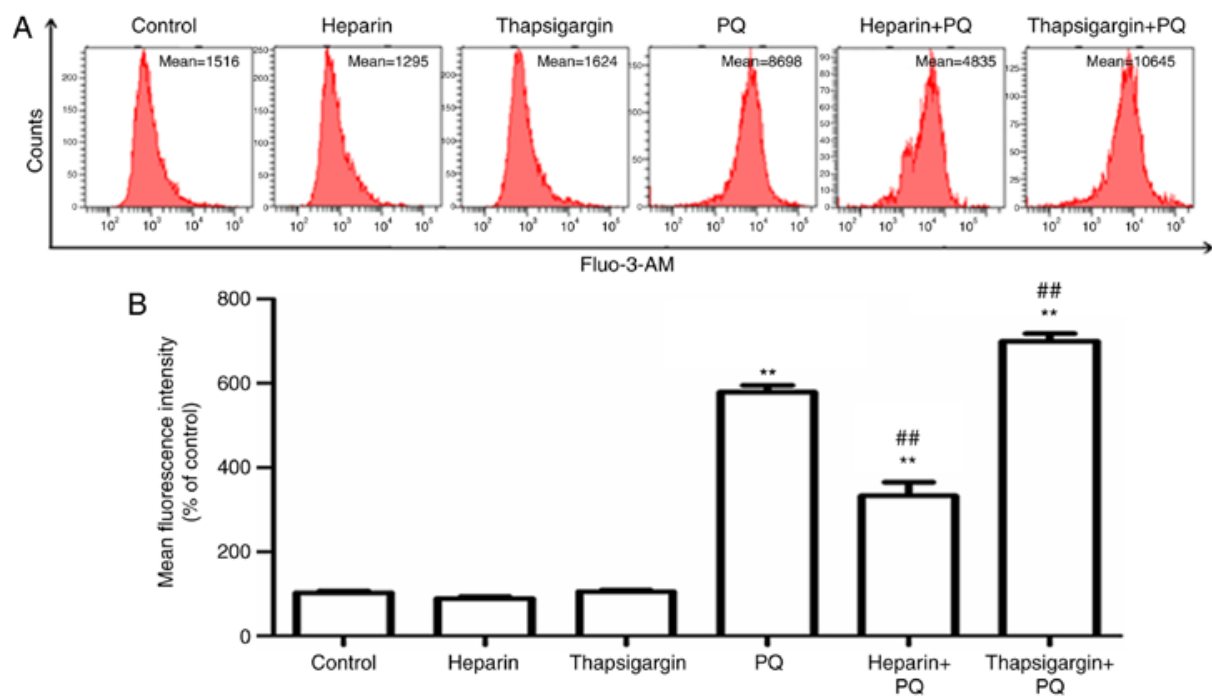

Figure 4. A549 cells were processed accordingly in the different groups for $48 \mathrm{~h}$, and then changes in $\mathrm{Ca}^{2+}$ concentration in the cells were detected using a flow cytometer. (A) Flow cytometric analysis and (B) statistical analysis of $\mathrm{Ca}^{2+}$ fluorescence intensity in each group. ${ }^{* *} \mathrm{P}<0.01$ vs. control group; ${ }^{\# \#} \mathrm{P}<0.01 \mathrm{vs}$. $\mathrm{PQ}$ group. $\mathrm{PQ}$, paraquat; $\mathrm{Ca}^{2+}$, calcium. 
A

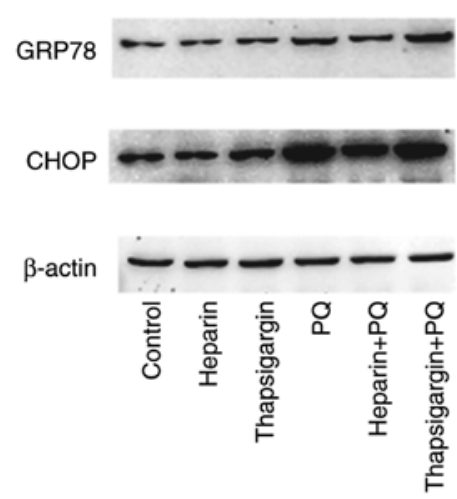

B

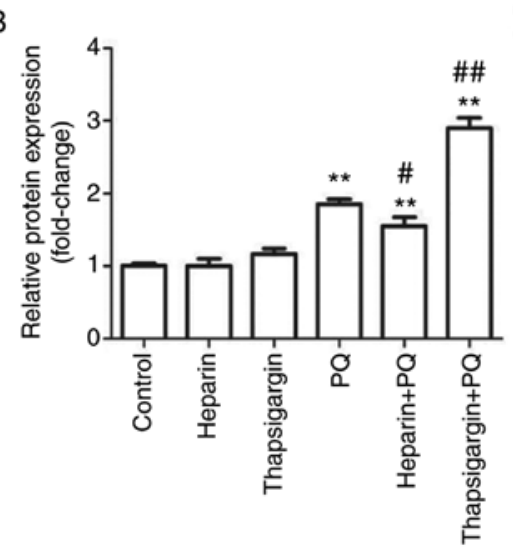

C

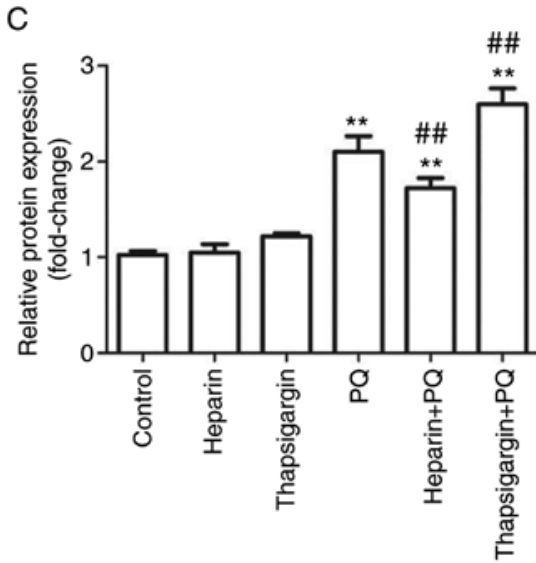

Figure 5. A549 cells were processed accordingly in the different groups for $48 \mathrm{~h}$, and then the protein expression levels of GRP78 and CHOP were detected by western blotting. (A) Western blotting results are shown. Statistical analysis of the protein expression levels of (B) GRP78 and (C) CHOP. ${ }^{* *} \mathrm{P}<0.01$ vs. control group; $\mathrm{P}<0.05$ and ${ }^{\# \#} \mathrm{P}<0.01$, vs. $\mathrm{PQ}$ group. $\mathrm{PQ}$, paraquat; GRP78, glucose-regulated protein 78; CHOP, C/EBP homologous protein.

and caspase-12 were increased by different degrees in the PQ, heparin + PQ and thapsigargin + PQ groups as compared with the control group. However, compared with the PQ group, the activities of caspase-7 and caspase-12 were significantly decreased in the heparin $+\mathrm{PQ}$ group, but significantly increased in the thapsigargin $+\mathrm{PQ}$ group (Fig. 6). These results revealed that intervention of $\mathrm{Ca}^{2+}$ signals in the ER has an effect on A549 cell apoptosis mediated by the ERS induced by PQ.

\section{Discussion}

The lung is the main target organ of $\mathrm{PQ}$ poisoning. Lung damage caused by PQ mainly manifests as pulmonary congestion,

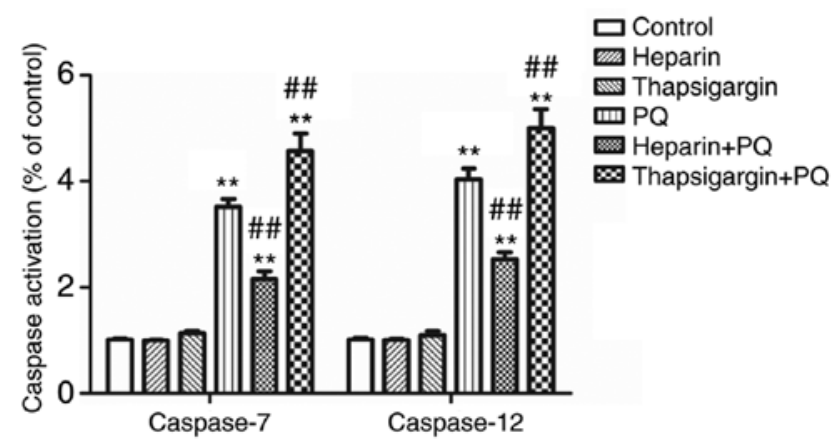

Figure 6. A549 cells were processed accordingly in the different groups for $48 \mathrm{~h}$, and then changes in caspase-7 and caspase-12 activities were detected. ${ }^{* *} \mathrm{P}<0.01$ vs. control group; ${ }^{\# \#} \mathrm{P}<0.01$ vs. $\mathrm{PQ}$ group. $\mathrm{PQ}$, paraquat.

bleeding, edema, the formation of a hyaline membrane, degeneration, hyperplasia and fibrosis, resulting in acute lung injury and acute respiratory distress syndrome. Even when patients have survived through the acute phase, they may succumb due to respiratory failure caused by irreversible pulmonary fibrosis $(12,13)$. Certain studies have suggested that the apoptosis of lung epithelial cells serves an important role in lung injury caused by PQ $(3,4)$. Therefore, it would be of great importance to illustrate the mechanism of lung epithelial cell apoptosis induced by PQ.

Cell apoptosis is an ordered, programmed and active type of cell death, and is the normal physiological response of the cell nucleus stimulated by specific signals. However, abnormal cell apoptosis is associated with the occurrence of numerous diseases (14). The cell apoptosis regulation mechanism is complex, and the cell apoptosis pathway differs according to the different environments, types of cells or stimulations (15).

$\mathrm{Ca}^{2+}$ signals are responsible for various basic cell functions, and once the concentration of $\mathrm{Ca}^{2+}$ or its regulation function becomes abnormal, $\mathrm{Ca}^{2+}$ homeostasis is lost. Hence, a series of cascade reactions are activated, and cell apoptosis or death finally occurs $(16,17)$. The ER is a membranous duct system distributed in the cytoplasm and is involved in material transportation in cells. $\mathrm{Ca}^{2+}$ concentration in cells is mediated by the ER, since $\mathrm{Ca}^{2+}$ is mainly stored in the ER. At present, studies have indicated that among all organelles, the ER is mainly in charge of the dynamic equilibrium of $\mathrm{Ca}^{2+}(18)$.

The present study suggested that PQ exposure was able to increase the $\mathrm{Ca}^{2+}$ concentration in cells and cause $\mathrm{Ca}^{2+}$ overload. When cells were preprocessed with thapsigargin to inhibit the ER from absorbing $\mathrm{Ca}^{2+}$, the $\mathrm{Ca}^{2+}$ concentration in the cytoplasm was further increased, indicating that the increase of $\mathrm{Ca}^{2+}$ concentration in the cytoplasm is correlated with the decrease in $\mathrm{Ca}^{2+}$ in the ER. By contrast, when cells were preprocessed with heparin to inhibit the release of $\mathrm{Ca}^{2+}$ in the ER, the $\mathrm{Ca}^{2+}$ concentration in the cytoplasm was decreased, indicating that the decrease in $\mathrm{Ca}^{2+}$ concentration in the cytoplasm is correlated with the decreased release of $\mathrm{Ca}^{2+}$ in the ER. These results suggested that PQ damaged the balance of $\mathrm{ER} \mathrm{Ca}^{2+}$ release and absorption, and led to $\mathrm{Ca}^{2+}$ overload in the cytoplasm. $\mathrm{Ca}^{2+}$ overload in the cytoplasm can trigger the mitochondrial pathway apoptosis (19). In the current study, MTT assay, Annexin V-FITC/PI double staining and Hoechst 33258 staining were conducted to further reveal that thapsigargin evidently enhanced the cytotoxicity and apoptosis levels induced by PQ treatment. By contrast, 


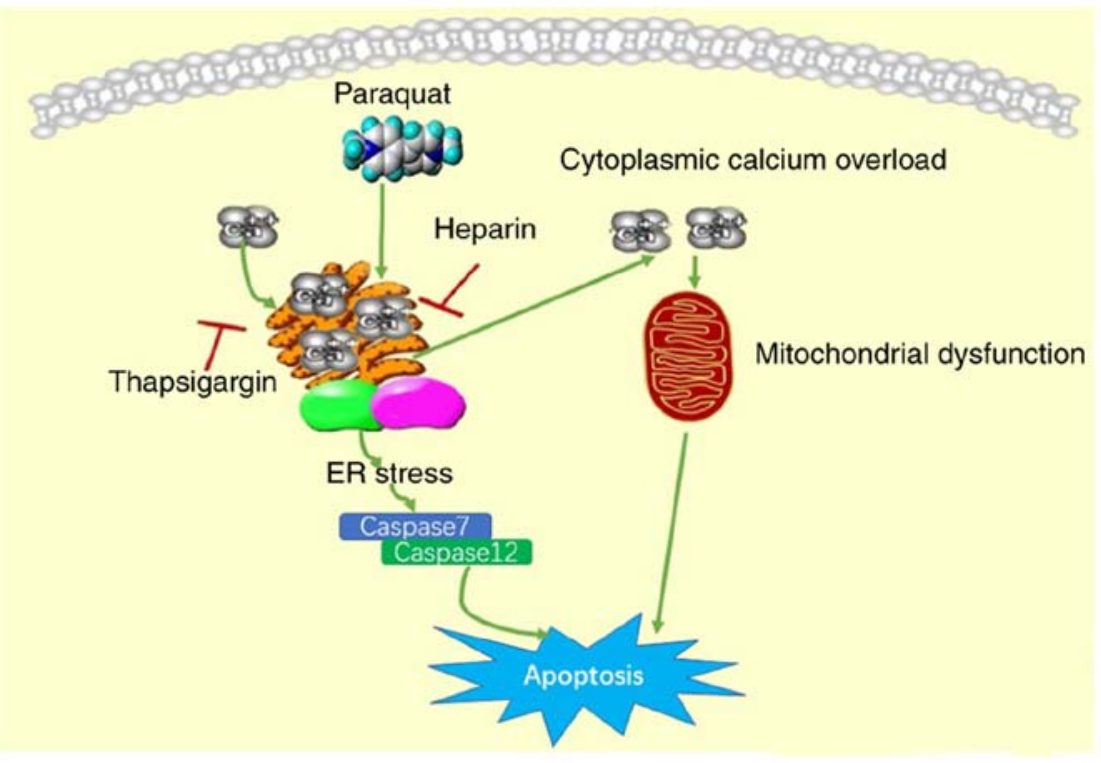

Figure 7. Mechanisms involved in ER calcium in PQ-induced A549 cell apoptosis. PQ, paraquat; ER, endoplasmic reticulum.

heparin was observed to inhibit the release of $\mathrm{Ca}^{2+}$ in the ER and evidently reverse the cell apoptosis induced by PQ. These findings further indicated that PQ induced cell apoptosis by damaging the $\mathrm{Ca}^{2+}$ homeostasis in the ER.

GRP78 is the molecular chaperone of ERS, and serves a critical role in maintaining ER protein synthesis, properprotein folding and $\mathrm{Ca}^{2+}$ homeostasis in cells; thus, it is an important marker of ERS (20). CHOP, as the enhancer binding protein and homologous protein of CCAAT, is a pro-apoptotic protein that is highly expressed during ERS, while it exhibits low expression in the absence of ERS; therefore, it can serve as a marker protein of ERS (21). An increasing number of studies have suggested that cell apoptosis induced by ERS is implemented by the activation of caspase- 7 and caspase-12 $(22,23)$. In the present study, PQ was found to markedly increase the expression levels of GRP78 and CHOP, which are relevant markers of ERS, as well as enhance the activities of caspase-7 and caspase-12 (as summarized in Fig. 7). Preprocessing with thapsigargin significantly increased the expression levels of GRP78 and CHOP, and the activities of caspase-7 and caspase-12 in PQ-treated cells. By contrast, preprocessing with heparin markedly reversed the effects of PQ in cells. These findings indicated that the intervention of $\mathrm{Ca}^{2+}$ had an effect on A549 cell apoptosis mediated by PQ through the ER pathway.

All apoptotic pathways eventually activate caspase-3, and thus caspase- 3 is a non-specific marker for certain apoptotic pathways. Other Caspases, such as caspase- 8 and caspase-9, that are activated by special apoptotic pathways have been reported $(24,25)$. Caspase-12, which is located in the adventitia of the ER, is a key molecule that mediates ERS-induced apoptosis and is only correlated with the mechanism of ERS-mediated apoptosis. There are several methods of caspase-12 activation induced by ERS, including $\mathrm{Ca}^{2+}$-dependent calpain activation and the caspase-7 pathway. Therefore, caspase-12 and the associated caspase-7 were investigated in the present study.

In conclusion, the results of the present study revealed that PQ had an effect on A549 cells by damaging the regulatory function of $\mathrm{Ca}^{2+}$ in the ER, which consequently resulted in $\mathrm{Ca}^{2+}$ overload and ERS, and triggered cell apoptosis. Furthermore, the study results suggested that, at the early stages of PQ poisoning, a considerable therapeutic strategy may be to prevent the $\mathrm{ER} \mathrm{Ca}^{2+}$ release, maintain the $\mathrm{Ca}^{2+}$ homeostasis in the ER and cytoplasm, and prevent the apoptosis of lung epithelial cells.

\section{Acknowledgements}

Not applicable.

\section{Funding}

This research was supported by The Doctoral Scientific Research Foundation (Liaoning, China; grant no. 20141033).

\section{Availability of data and materials}

The datasets used and/or analyzed during the current study are available from the corresponding author on reasonable request.

\section{Authors' contributions}

XSD designed the study. QC analyzed the data. CY made substantial contributions to conception and design. CQS, DZS and YMX conducted the experiments. All authors reviewed, edited and approved the final version of the manuscript.

\section{Ethics approval and consent to participate}

Not applicable.

\section{Patient consent for publication}

Not applicable.

\section{Competing interests}

The authors declare that they have no competing interests. 


\section{References}

1. Serra A, Domingos F and Prata MM: Paraquat intoxication. Acta Med Port 16: 25-32, 2013 (In Portuguese).

2. Ko DR, Chung SP, You JS, Cho S, Park Y, Chun B, Moon J, Kim H, Kim YH, Kim HJ, et al: Effects of paraquat ban on herbicide poisoning-related mortality. Yonsei Med J 58: 859-866, 2017.

3. He Y, Zou L, Zhou Y, Hu H, Yao R, Jiang Y, Lau WB, Yuan T, Huang W, Zeng Z and Cao Y: Adiponectin ameliorates the apoptotic effects of paraquat on alveolar typecells via improvements in mitochondrial function. Mol Med Rep 14: 746-752, 2016.

4. Zhao G, Cao K, Xu C, Sun A, Lu W, Zheng Y, Li H, Hong G, Wu B, Qiu Q and Lu Z: Crosstalk between mitochondrial fission and oxidative stress in paraquat-induced apoptosis in mouse alveolar type II cells. Int J Biol Sci 13: 888-900, 2017.

5. Wang R, Sun DZ, Song CQ, Xu YM, Liu W, Liu Z and Dong XS Eukaryotic translation initiation factor 2 subunit $\alpha$ (eIF2 $\alpha$ ) inhibitor salubrinal attenuates paraquat-induced human lung epithelial-like A549 cell apoptosis by regulating the PERK-eIF2 $\alpha$ signaling pathway. Toxicol In Vitro 46: 58-65, 2018

6. Marchi S, Patergnani S, Missiroli S, Morciano G, Rimessi A, Wieckowski MR, Giorgi C and Pinton P: Mitochondrial and endoplasmic reticulum calcium homeostasis and cell death. Cell Calcium 69: 62-72, 2018.

7. McIlwain DR, Berger T and Mak TW: Caspase functions in cell death and disease. Cold Spring Harb Perspect Biol 5: a008656, 2015.

8. Sehgal P, Szalai P, Olesen C, Praetorius HA, Nissen P, Christensen SB, Engedal N and Møller JV: Inhibition of the Sarco/endoplasmic reticulum (ER) $\mathrm{Ca}^{2+}$-ATPase by thapsigargin analogs induces cell death via $\mathrm{ER} \mathrm{Ca}^{2+}$ depletion and the unfolded protein response. J Biol Chem 292: 19656-19673, 2017.

9. Hammadi M, Oulidi A, Gackière F, Katsogiannou M, Slomianny C, Roudbaraki M, Dewailly E, Delcourt P, Lepage G, Lotteau S, et al: Modulation of ER stress and apoptosis by endoplasmic reticulum calcium leak via translocon during unfolded protein response: Involvement of GRP78. FASEB J 27: $1600-1609,2013$

10. Szikra T and Krizaj D: The dynamic range and domain-specific signals of intracellular calcium inphotoreceptors. Neuroscience 141: 143-155, 2006.

11. Zhivotovsky B and Orrenius S: Calcium and cell death mechanisms: A perspective from the cell death community. Cell Calcium 50: 211-221, 2011.

12. Shao $X$ and Chen JH: Progress on pathogenesis and treatment of paraquat-induced pulmonary fibrosis. Zhejiang Da Xue Xue Bao Yi Xue Ban 43: 717-727, 2014 (In Chinese).
13. Dinis-Oliveira RJ, Duarte JA, Sánchez-Navarro A, Remião F, Bastos ML and Carvalho F: Paraquat poisonings: Mechanisms of lung toxicity, clinical features, and treatment. Crit Rev Toxicol 38: 13-71, 2008.

14. Bursch W, Oberhammer F and Schulte-Hermann R: Cell death by apoptosis and its protective role against disease. Trends Pharmacol Sci 13: 245-251, 1992.

15. Evans VG: Multiple pathways to apoptosis. Cell Biol Int 17: 461-476, 1993.

16. Felsenfeld A, Rodriguez M and Levine B: New insights in regulation of calcium homeostasis. Curr Opin Nephrol Hypertens 22: 371-376, 2013.

17. Hajnóczky G, Davies E and Madesh M: Calcium signaling and apoptosis. Biochem Biophys Res Commun 304: 445-454, 2003.

18. Sun DP, Li XX, Liu XL, Zhao D, Qiu FQ, Li Y and Ma P: Gypenosides induce apoptosis by $\mathrm{Ca}^{2+}$ overload mediated by endoplasmic-reticulum and store-operated $\mathrm{Ca}^{2+}$ channels in human hepatoma cells. Cancer Biother Radiopharm 28: 320-326, 2013.

19. Orrenius S, Gogvadze V and Zhivotovsky B: Calcium and mitochondria in the regulation of cell death. Biochem Biophys Res Commun 460: 72-81, 2015.

20. Cho H, Wu M, Zhang L, Thompson R, Nath A and Chan C: Signaling dynamics of palmitate-induced ER stress responses mediated by ATF4 in HepG2 cells. BMC Syst Bio 7: 9, 2013.

21. Guo G, Meng Y, Tan W, Xia Y, Cheng C, Chen X and Gu Z: Induction of apoptosis coupled to endoplasmic reticulum stress through regulation of CHOP and JNK in bone marrow mesenchymal stem cells from patients with systemic lupus erythematosus. J Immunol Res 2015: 183738, 2015.

22. Mills E, Chen X, Pham E, Wong S and Truong K: Engineering a photoactivated caspase-7 for rapid induction of apoptosis. ACS Synth Biol 1: 75-82, 2012.

23. Zhang Q, Liu J, Chen S, Liu J, Liu L, Liu G, Wang F, Jiang W, Zhang $\mathrm{C}$, Wang $\mathrm{S}$ and Yuan $\mathrm{X}$ : Caspase-12 is involved in stretch-induced apoptosis mediated endoplasmic reticulum stress. Apoptosis 21: 432-442, 2016.

24. Zhang JY, Lin MT, Tung HY, Tang SL, Yi T, Zhang YZ, Tang YN, Zhao ZZ and Chen HB: Bruceine D induces apoptosis in human chronic myeloid leukemia K562 cells via mitochondrial pathway. Am J Cancer Res 6: 819-826, 2016.

25. Lin M, Tang S, Zhang C, Chen H, Huang W, Liu Y and Zhang J: Euphorbia factor L2 induces apoptosis in A549 cells through the mitochondrial pathway. Acta Pharm Sin B 7: 59-64, 2017. 